MILLENNIAL READERS: AN ANALYSIS OF YOUNG ADULT ESCAPISM

\author{
by \\ Marina Demetriou \\ BA, English, Carleton University, 2016 \\ Publishing Certificate, Ryerson University, 2017 \\ A Major Research Paper \\ presented to Ryerson University \\ in partial fulfillment of the \\ requirements for the degree of \\ Master of Arts \\ in the English MA Program \\ in Literatures of Modernity
}

Toronto, Ontario, Canada, 2020

(C)Marina Demetriou, 2020 


\section{AUTHOR'S DECLARATION FOR ELECTRONIC SUBMISSION OF A MAJOR RESEARCH PAPER}

I hereby declare that I am the sole author of this MRP. This is a true copy of the MRP, including any required final revisions.

I authorize Ryerson University to lend this MRP to other institutions or individuals for the purpose of scholarly research. I further authorize Ryerson University to reproduce this MRP by photocopying or by other means, in total or in part, at the request of other institutions or individuals for the purpose of scholarly research.

I understand that my MRP may be made electronically available to the public. 


\author{
Marina Demetriou \\ Master of Arts in the English MA Program \\ Ryerson University's Literatures of Modernity, 2020
}

\title{
ABSTRACT \\ Millennial Readers: An Analysis of Young Adult Escapism
}

The emphasis on the generational identity of American millennials and their portrayal in the current cultural landscape of the twenty-first century furthers the idea that millennials are exhibiting escapist tendencies by engaging themselves as a majority (fifty-five percent) of young adult readership ("New Study"). Born within 1981 and 1996, millennials (also known as Generation Y) are defined, as those that are-for reasons such as student debt, cost of living, and the financial crisis — delaying typical milestones of adulthood like obtaining a degree, securing a career, purchasing a house, and starting a family. This examination of the social and cultural factors that have affected twenty-first century American society exposes how authors have navigated a world increasingly defined by evolving identity, displacement, discrimination, and a generational lack of agency for the age-diverse young adult market. These themes-including Black Lives Matter, socio-economic hardships, and totalitarian power-have been written with younger audiences in mind, as authors attempt to mimic societal pitfalls within literature in an approachable narrative. The regression of adulthood and millennial priorities have evolved the young adult genre over the last twenty years (since the first millennials became adults), and as a result, they have generationally transitioned into a redefined version of adulthood that requires an escapist outlet. 
Young adult literature is traditionally comprised of bildungsroman-themed texts written for twelve to eighteen-year-old readers. This genre is presented in a multitude of fiction and nonfiction genres, including fantasy, mystery, memoir/autobiography, and romance. Young adult literature is critical to the development of a teenage audience, because it instills young adults with an interest in reading, as "stories are powerful because they engage the emotions, demand critical thinking, inspire independent reading, and free the imagination to visit the past, live differently in the present, and envision the future" (Latrobe xi). Despite the intended audience, many preteens may have to stretch their understanding, but will most likely not encounter material inappropriate for them within this genre (Rosenberg). Meanwhile, adults will find a similarity and familiarity in the stories that they can also connect with as it "drives cultural engagement" for all American readership, including the prominent millennial audience (Rosenberg). Born between 1981 and 1996, millennials, also known as Generation Y, are defined as those who are delaying typical milestones of adulthood like obtaining a degree, securing a career, purchasing a house, and starting a family for reasons like student debt, the rising cost of living, and the current and past financial crises. According to two American studies, conducted in 2012 and 2015 by Publishers Weekly and Bowker Market Research, respectively, the majority (up to eighty percent) of young adult readers are adults with over twenty-five percent being in the thirty to forty-four-year-old range. Evidently, young adult literature is read by older audiences—including millennials—who prefer this genre's focus on lighter topics, because they are reflective of millennials' real-life experience of being within an eternal transition period. This period coincides with American millennials' nostalgia for a childhood naivete regarding contemporary world issues before bigoted ideologies about microaggressions and systemic racism, global warming, and patriarchal gendered expectations affected their worldview. This is 
synonymous with millennials' delayed progress, as millennials believe that the process of becoming an adult resides on educational and economic accomplishments over previous adulthood ideals such as marriage and parenthood. For those eighteen to thirty-years-old readers, a new genre called "new adult fiction" was created in 2009; it was meant to bridge the gap between young adult and adult fiction. This genre converged issues prevalent in typical bildungsroman fiction with conventional benchmarks of adulthood—going to university, getting a job, buying a house, and starting a family. Despite this new genre, adult readers have had a significant impact on the young adult market that has thrived in the last fifteen years because of an age diverse readership, which characterizes this literature as crossover fiction ("Publishing Statistics"). Emphasizing the generational identity of millennials and their portrayal in America's cultural landscape furthers the idea that millennials are exhibiting escapist tendencies by engaging themselves as a vast majority (fifty-five percent) of young adult readership ("New Study"). Examining the social and cultural factors that have affected modern society exposes how authors have journeyed through a world increasingly defined by evolving identity, displacement, discrimination, and a generational lack of agency for the age-diverse young adult market. These themes have been written with younger audiences in mind, as authors attempt to mimic societal pitfalls through an approachable literary narrative.

According to a study published in Business Insider, the average American millennial is financially lagging, they are faced with a "high cost of living, staggering student-loan debt, and the fallout of the Great Recession" as they traverse through The Great American Affordability Crisis (Hoffower). With marked up living costs (for rent and home prices), the astronomical price of tuition, and limited wage increases, millennials, in general, are plagued by a financial crisis that the generations that came before did not have to endure. More than half of typical 
American millennials are financially dependent on a parent or guardian, with the money going toward "basic needs, both small and significant, like cellphone bills, groceries and gas, health insurance, and rent" (Hoffower). Due to this financial instability, millennials are delaying homeownership, because they are forced to rent for longer and buy later in life. Notably, with homes being thirty-nine percent more expensive than they were forty years ago, it is inevitable that millennial homeownership was at a record low in 2017 (Hoffower). This delay has also moved into marriage as well, as millennials are prioritizing financial stability and taking more time to find the right partner-in 1980, the median age of marriage was twenty-two for women and twenty-five for men, while in 2020 it is twenty-seven for women and twenty-nine for men (Hoffower). This delay in marriage means millennials are having children later in life, with the birthrate in the United States at its lowest in the last three years with more women in their thirties having babies than in their twenties for the first time - partially due to the high cost of raising a child (Hoffower).

Stereotypes believe millennials to be lazy, debt-ridden, demanding and unrealistic in their career aspirations, internet-addicted, and lonely. The reality of the social and economic factors of American society means that millennials have much less agency than many give them credit for (Woods). Millennials struggle just to survive day-to-day, and they clearly require an escapist outlet. Merriam-Webster's dictionary defines escapism as the "habitual diversion of the mind to purely imaginative activity or entertainment as an escape from reality or routine.” Escapist literature can refer to any narrative that has the ability to take a reader to an alternate universe written within the book's pages. Despite its negative connotations that suggest an innate unhappiness and inability to substantially connect with the world, escapism can be considered a creative space that allows a person to reimagine the problems of their social reality. As an 
imaginative engagement, escapist literature transports readers for much-needed psychological relief of the tedium of their life. Within young adult literature, adult readers find a comfortable nostalgia, happiness, and fulfillment, that acts as a refuge for the reality of their unfulfilled adulthood signifiers, and as a way to better understand the world around them.

As the COVID-19 lockdown persists, the reality is that escapist literature is needed even more so now than ever. Millennials graduating from higher education continue to be unable to obtain a job, and those who have acquired a career have been laid off and are in more financial strife than ever. With this pandemic came outrageous unemployment rates with fifty-five percent of Americans under forty-five affected negatively with lay-offs, cut hours, or furloughed (Collins). Those between the ages of eighteen and twenty-nine are the most impacted by layoffs, as forty-five percent in this age range have reported reduced wages in their household (Collins). Now, millennials are given the option to divert mortgage and credit card payments, which means that those who were able afford the purchase of a house have financial security in the form of advantageous options (Nova). Especially since homeowners have the option to liquidate their assets in order to provide for their own basic needs without suffering any eventual causalities that borrowing money (with interest) will cost. This indicates that financial security for millennials is even harder to obtain, as not only are millennials financially dependent on their parents, but they are forced to rely on government subsidies in order to survive through their basic monthly expenses. This uncertainty will cause more millennial adults to turn to literary escapism that is a saving grace in the form of young adult literature. According to Booknet Canada, the number of romance and romantic-comedy book purchases has increased by $280 \%$ percent from mid-March to mid-April when compared to figures from 2019 (Hirchberg). Within the same parameters, fantasy/urban genre has increased by 153\% (Hirchberg). These figures 
demonstrate that escapism is necessary when stressful economic and social situations require an outlet. Escapism is not a new concept as this trend has continued since the beginning of the twenty-first century, especially during America's recession, political shifts, and the fight against terrorism that has occurred in the last few decades.

Erik Erikson was a developmental psychologist and psychoanalyst who believed that individuals go through eight developmental stages in which they must "face and cope with a central psychosocial problem or crisis": "basic trust versus mistrust, autonomy versus shame and doubt, initiative versus guilt, industry versus inferiority, identity versus identity confusion, intimacy versus isolation, generativity versus stagnation, and ego integrity versus despair" (Munley 314). With a merging of social factors, thoughts, and behaviours, one goes through each crisis stage, from birth to death, to develop and shape their personality (Munley 314). The fifth stage of Erikson's theory, that adolescents must have a crisis of identity versus role confusion, explores the idea that teenagers are tasked with creating their own identity through environmental and personal factors, as well as the development of goals and values. Once an identity is developed, the next step in Erikson's theory centres those in their twenties and thirties as they form intimate and fulfilling relationships. For those that fail to create these connections, they are shrouded in isolation and loneliness. Millennials are unable to fulfil their own personal goals, nor have they been able to develop an identity beyond the millennial title. They cannot identify themselves as a young adult with personal and professional goals and responsibilities and are delayed in classifying themselves as an adult with a high level of adult responsibilities. Instead, American millennials are prematurely skipping over the sixth stage and seem to be moving onto the seventh, generativity versus stagnation stage. This stage encompasses adults' need to create and nurture in order to leave behind a legacy that outlasts them (Slater 57). If 
one's procreation is delayed or halted completely, they are driven to contribute to society in different ways that benefit others. If not, a stagnant feeling develops as one does not fulfil their need to be considered a productive member of society. This can lead to new adults believing that they are imposters when it comes to adulthood. Imposter syndrome is a psychological term that refers to a "pattern of behavior wherein people (even those with adequate external evidence of success) doubt their abilities and have a persistent fear of being exposed as a fraud" (Mullangi). This debilitating fear that one, no matter their age, is not performing as an adult adequately enough is the catalyst that caused both new adult and young adult fiction to become popular with millennials.

The jumble of millennial's life stages is what Erickson would call "prolonged adolescence," but this idea is short-sighted in that it refers to a very distinct emotional immaturity that disregards the experiences through which this generation of readers (and those thereafter) has developed (Erickson qtd. in Pattee 220). Millennials' lived experiences have resulted in a generation of emerging adults, quite dissimilar to adolescence, that have "reached their majority and enjoy the rights and privileges associated with this milestone; furthermore, they form peer communities in and around institutions of postsecondary education and engage in serious romantic relationships" (Pattee 220). Those individuals in this group associate themselves with neither the label of adolescent nor adult — they are a new adult in an in-between classification. James E. Côté is a sociologist whose work attempts to disprove this idea of emerging adulthood as a new developmental stage that all individuals need to progress through in order to enter into adulthood. Côté believes that emerging adulthood is a metanarrative of individual responses to "interactions of various elements, such as self-agency, individual life experiences and health, relationships, economic and social changes, structural forces, and a 
problematic labour market" (Hendry and Kloep qtd. in Pattee 220). While both new adult and young adult fictions are distinct in their literary journeys, there are some issues that are commonly depicted in both. Especially, themes like sexuality, bildungsroman (coming-of-age), and "emotionally-intense storylines and fast-paced plotting" that are often associated with young adults' — and now new adults'—growth into a new stage of life through literature (Wetta qtd. in Pattee 220). The narrative style is also similar as both focus on a first-person protagonist and narrator. This tends to blur the line between the two genres, with the only difference being how much sexual conduct is included in the book (Pattee 220). New adult literature may include graphic scenes while young adult literature must be tamer for the younger teenage audience even as sexual practice is considered a part of the coming-of-age experience (Pattee 220). This censorship of specific themes examined in young adult literature has occurred frequently in the twenty-first century. These novels are believed to be the reality of a young adult's experience as it exposes the "realities of racism or encouraging the spirit of the individual" while protagonists develop and grow agency within the narrative (Greenwell 318). An example of a "frequently challenged" (or banned/censored) book is Judy Blume's Forever (1975), that explores female sexuality through the teenage protagonist's exploration of masturbation, a sexual relationship, and birth control. This censorship has created a prolonged emerging of adulthood, one that is not defined by a specific age group, as the first stage is considered the "emotional preparation for the journey being represented in young adult literature, then the journey itself showcased in [new adult literature]" (Brookover, Burns, and Jensen qtd. in Pattee 220).

Cross-writing, with the texts produced by authors categorized as crossover literature, allowed for a blurred line between 'adult' and 'child' material which was based on a "sensibility that demands the child reader's interaction with adult political and social concerns" (Smith 2). 
This official merging of literatures continued the difficulty readers of contemporary literature have differentiating between children and adulthood themes. Classical novels like Jonathan Swift's Gulliver's Travels (1726), Bram Stoker's Dracula (1897), and Daniel Defoe's Robinson Crusoe (1719) were not intended for young children, but they were read by younger audiences anyway who then claimed these books for themselves (Anggraini 3). These books are clearly considered classics and have been continuously, "republished for children by printing abridged additions" (Anggraini 3). The literary classification system was not made specifically for readers as they choose which books they were interested in and read them with no qualms for the intended audience. Therefore, the borders between children's, young adult, and adult literature is nonexistent in reader's minds (Anggraini 2). Instead this classification system was "made by academia or by publishers responsible for marketing the books" (Anggraini 2). Some publishers would publish the same book multiple times with different targeted visuals so they could appeal to both adult and child readers. A famous example of this is Harry Potter and the Philosopher's Stone (1997), or Harry Potter and the Sorcerer's Stone, that had multiple different covers with each being used to appeal to audiences of all ages (Anggraini 2). In 2001, Harry Potter was not the only young adult series popular with all audiences, Philip Pullman's The Amber Spyglass (2000) won the Children's Book category of the Whitbread/Costa Award and then the overall Book of the Year award as well. This series, just like J.K. Rowling's, also had a few print runs that were intended to visually appeal to adults, as well as teenagers and preteens. The reality is that crossover literature has financial significance and the publishing world has to reprint different editions of the same novel in order to support a seamless crossover for all ages. Adults have obviously become a very big part of the publishing world in that they are inspiring an evolution of how works are marketed to readers. An example of the potential between the 
advancement of society and its effect on literature occurred during the Harlem Renaissance, which spanned much of the 1920s. the Harlem Renaissance was heavily impacted by W. E. B. Du Bois, an academic and civil rights activist who was one of the founders of the National Association for the Advancement of Colored People (NAACP) in 1909. Du Bois also fought against the caricature of the African-American child and adult, and he "reimagined the black child as culturally, politically, and aesthetically sophisticated. This new vision was absolutely necessary to the triumph of the New Negro movement, since social change and artistic recognition would come through the work of the progressive younger generation" (Smith 1-2). Du Bois advanced the NAACP's campaigns against lynching and social injustice by establishing "expectations for a politically savvy and involved child reader" (Smith 2). Black childhood was recreated under the tutelage of Du Bois and profoundly impacted the literary and political spheres (Smith 2). Du Bois' inception of both "Crisis," the official magazine of the NAACP, and “The Brownies' Book," made it necessary for readers to reconsider conventional separation of children and adult texts, because the maturity of the young reader could not be overlooked (Smith 4). The Eurocentric ideas surrounding children's books at this time meant that texts were only for those younger than twelve years of age, like Beatrix Potter's The Tale of Peter Rabbit (1901), Louisa May Alcott's Little Woman (1868), and Alice's Adventures in Wonderland (1865) by Lewis Carroll. On the contrary, Black children were believed to be the ones to further social progress; education- and literacy-wise, these children were closer to the level of adults or surpassed them and were considered, as young readers and characters, to be in a "position of power over adults that we do not usually associate with children's literature" (Smith 4). "The Brownies' Book" was the first magazine published for African American children and young 
adults began during the Harlem Renaissance and contained the new concept of "cross writing" (Smith 2).

This lived experience of an in-between or crossover generation does not end with millennials, but will continue to disrupt the next generation, Generation Z, as they attempt to navigate a society and collectivism heavily impacted by digital culture that continues to redefine adulthood signifiers. The use of emerging social media like TikTok and Instagram will have a long-term impact, as it entices a compulsivity to watch the glamorous lives of others and create new internet dances and challenges that connect the younger generations. In 2014, when Facebook was a popular social media platform for young adults, authors Tom Ellen and Lucy Ivison released a young adult novel entitled Lobsters (2014) that mentioned Facebook in order to showcase a relevancy to present day young adult topics. Often, social media in literature can be a distraction that hinders the storyline and message of a text; especially, as the misguided focus deviates from fully developing a character's growth and the story's plot development. Lobsters, in contrast, does not overshadow the importance of bildungsroman themes, but focusses on the lives of the young adult characters whose existences do not revolve completely around social media. For other young adult texts, social media encompasses the story and characters, like in Lauren Myracle's Internet Girls series: TTYL (2004), TTFN (2006), L8R, G8R (2007), and YOLO (2014), with the narrative completely in instant messages (IMs), text messages, and other electronic communication. This series, in contrast to Lobsters, shows the ways in which technology has taken over the lives of some of the youth who know nothing other than life with a smartphone in hand. In Myracle's series, the discussions between the three friends ranges from making plans to meet at Starbucks to going to Planned Parenthood to get a prescription for birth control pills. Young adult literature tends to focus on being light and funny which means that 
oftentimes, authors writing about these important topics can oversimplify and trivialize the experiences of young adults. An example of this in Myracle's series is her depiction of her three main characters, who progress through the series but completely lose their individual identities in order to sound more like what Myracle believes to be the linguistic nuances of young adults. The narrative voice changes from a more articulate group of best friends to them continuously messaging things like "(((HUGS)))" and "I haz" instead of "I have." In the last book of the series, a running joke was one character's personality changing to embody the stereotypical idiocy of youth, shown when this character is unable to understand when someone corrects her text that wrote "Reid and me" to the grammatically correct "Reid and I." This can be seen as a collective infantilizing of millennials and Generation $\mathrm{Z}$ in order to distract them from being able to create their own identity and determine their self-worth and goals. Notably, the themes that harmfully affect the identity of millennials and Generation $\mathrm{Z}$ are displacement, discrimination, and an enviousness of false-glamourous lives seen on social media. This shared experience of society's digital influences, as well as the continued delay in adulthood, should classify Côté's emerging adulthood and Erikson's prolonged adolescence — merged for their similarities—as a stage through which millennials, and those, thereafter, have to progress. The theory of emerging adulthood was proposed to account for the demographic changes of those in the eighteen to twenty-nine-year-old age range to consider the "rise in college participation," as well as the delay in adulthood signifiers (Murray 1). It is clear, then, that young adult and new adult fiction both have a distinct use and relevance that exposes the fact that this is a developmental stage in itself rather than simply a prolonged adolescence.

This developmental stage that millennials and Generation $\mathrm{Z}$ have to progress through has a specific relevance to the relationship between literature and society. An example of this is 
within Suzanne Collins' The Hunger Games (2008) that may seem to focus on a stereotypical love triangle between the three main characters Katniss, Peeta, and Gale when in reality it "criticized the social and economic gaps found in different societies in the world" (Anggraini 68). The Hunger Games is an allegory of the political and social landscape that persists in America's twenty-first century. Especially, through the blatant criticism of authority that Katniss displays as she manipulates the live-or-die game she is enrolled in so that there are multiple winners. The urging of individualism, instead of the blind following of authority, is seen in Collin's series especially in the symbolism of mockingjays. Mockingjays are considered a mixed-breed bird, a blend of the engineered birds that spy for the Capitol—the "utopian" ruling body full of powerful citizens — and wild, free birds. Mockingjays inherently symbolize the failure of the Capitol, as they represent a "perfect symbol of defeat of the Capitol" who were unable to create effective spy machines (Anggraini 178). This is an important theme often included within young adult literature, because one's agency is completely merged with their identity development. This can be seen in the current cultural context of America in 2020, there is a clear uneasiness for women and people of colour with President Donald Trump in power, as Trump's leadership is steeped in white supremacy and blatant racism and misogyny. Even though Collins' series was published much earlier than President Trump's inauguration, there is a clear connection between key American events that shaped the generation (like the failing economy in the 2000s) to the millennial experience of requiring escapist literature. Previous to The Hunger Games' release, President George W. Bush's (in office from 2001 to 2009) administration was steeped in controversy surrounding the terrorist attack on the twin towers in New York and the subsequent invasion of Iraq. This has exposed a dangerous reality for many Americans that is similar to the idea of a totalitarian governing body, like that in The Hunger 
Games. Katniss' agency is inspiring to those who feel powerless with the harrowing realities of adulthood plaguing millennials and Generation Z. It is also important to note that Katniss Everdeen must fight. Katniss (the good faction) fights the Capitol (the evil party) which is a totalitarian and controlling ruler that seems soulless and lacking a guilty conscience. Katniss thus embodies compassion as she has a need to help those she deems helpless. Katniss' tough stoic attitude is important to note, because she remains a very relatable character to many readers. Many teenagers feel that they need to keep an outward appearance of toughness so that the world and the world's problems do not tear them down. In this series, good always defeats evil which is an inspiring sentiment that does not always prove to be true in the non-literary world. In the real world, the ideas of good and evil are not easily distinguished as many people have qualities that are in a metaphorical grey area. America in the twenty-first century is a reality where the "bigevil" corporations are destroying earth's natural wildlife and ecosystems. Within the pages of a novel, there is a comfort knowing that future generations will not have to suffer the consequences they had no part in creating, like millennials' failing economy. As Rosenberg explains, young adult fiction is used to give hope to its readers. There is an underlying belief that suffering, and agony, always bring about some type of reward down the line- the change will later help generations not have to go through the same agonizing decisions as the generation before. Adult interest in young adult literature is clearly a form of escapism, because adults tend to know that the universe does not always bring about cosmic karma - the idea that there is a universal scale determining good and evil, and that good will always win.

In a world where a reader walks into an Indigo bookstore and immediately sees the different genres and subgenres of texts—-how does one series or book overcome the hurdle of being singularly categorized become a mass entertainment phenomenon? The Atlantic's Alyssa 
Rosenberg believes that "fans of all ages have flocked repeatedly to series aimed at young adults," because these novels and films fill a sweet spot in the market (Rosenberg). As new young adult series are released, they contain darker imagery that does not solely work to attract nostalgic adult readers. Instead, adults are interested in young adult literature because of the reality of the cultural emphasis on the "bleak, the dead, the escapist setting of something and somewhere else" that draws in all sorts of readers (Garcia 17). This interest is a sign of adult infantilization, because this dark emphasis is the reality of the contemporary culture of millennials (Falconer 3). According to an article written for Publisher's Weekly by Stacy Whitman, eighty percent of those reading young adult literature are adults purchasing the books for themselves which has thus pushed the genre into a "darker and more sophisticated place" (Whitman). This literary path is a commercial impulse to keep all readers interested in a newly released series. The genre's market is engaging with typical young adult themes of teenagers encountering "reflections of their own experiences there, that first striking confirmation that the agonies of adolescence are universal" with a darker focus (Rosenberg). For example, Harry Potter is orphaned by a homicidal terrorist, loses many of the people he looks up to, and has to give up his life in an epic struggle against evil. Twilight's Bella Swan (2005) suffers through a grotesque birthing of her child that eats away at her human body before she becomes a vampire alongside her spouse. Katniss Everdeen lives in a dystopian world where she has to fight for her life, loses her sister, and is a pawn in a revolution. Before these characters even reach a suitable age in the United States, they are put through so much strife which mimics the environment we live in today. These years we see more teenagers come forward to express their disappointment in the government and the way that certain things are handled, especially with reoccurring protests for gun violence and the Black Lives Matter movement. 
The first book that helped shift young adult literature to a new era of depicting realistic themes (like youths abusing drugs and societal teenage angst) was S.E. Hinton's 1967 novel The Outsiders. By exploring the social injustice of a couple of poor gang members against rich kids, this novel uniquely explored a realistic topic that had not been previously discussed. Following this era, series' like The Baby-Sitters Club (released in the 1980s) showcased the highconsequence of "teen pregnancy, substance abuse, mental illness and poverty," and relationship angst that embodies the true focus of young adult literature (Vallone). Angie Thomas' The Hate U Give (2017) reflects development of this genre over the last three decades to focus on realism and social issues as it tackles "institutional racism, police brutality, gangs, class conflict, interracial relationships, and poverty" (Vallone). Thomas's The Hate U Give is an excellent example of this positive influence as Starr Carter witnesses the shooting of her Black, unarmed childhood best friend at the hands of a white police officer. This topic realistically echoes stories we often see in recent American news stories related to violence and assault committed against young people of colour. Nineteen-year-old De'von Bailey was shot in the back by police (August 2019); D'ettrick Griffin was eighteen when he tried to steal a car — unarmed — and was shot by an out-of-uniform officer (January 2019); Ramarley Graham was another unarmed eighteenyear-old who was shot and killed in front of his family during an alleged drug bust gone awry (February 2012); Trayvon Martin was seventeen when he was unjustly shot and killed by a neighbourhood watch volunteer (February 2012) (Staff). These are just a few examples of the many African-American teenagers (and men) unjustly murdered because of excessive force and police violence. All of these murders exhibit the "deep problems of discrimination, racism, and class bias woven into the fabric of our criminal justice system, and of the American social order writ large" (Johnson xi). Negative stereotypes of African-Americans are still commonplace in 
Western culture, this culture of contempt, derision, and dehumanization of African-Americans exposes the reality that current social and cultural movements have not progressed as far as one — seeking equal rights for existential freedom—would hope. In response to these socioethnic preference of Eurocentric people and characters, African-American authors have attempted to navigate this world that has been defined by these questions of racism and diasporic identity. Especially, as these authors continue to impact the Black Lives Matter social movement. This media phenomenon was a direct result of the "number of lethal incidents between representatives of law enforcement and minority men" (Johnson 324). This topic is of significant importance to millennial readers because of a shared obligation to engage with socio-cultural issues and social justice politics.

This movement has already sparked some interesting social justice works like Tony Medina's graphic novel entitled I Am Alfonso Jones (2017) that follows a Black high school student, Alfonso, who is mistakenly shot and killed by a police officer. This contemporary take on the classic Hamlet storyline parallels Alfonso's experience in the afterlife with many wellknown police shooting victims, as well as the grief and justice that the Black Lives Matter group is attempting to seek on Alfonso and his family's behalf. This is another novel that exposes a weakness in society while doing so through the eyes of a young adult. By reading this novel, crossover readers are able to better understand the horrific reality of police discrimination and the senseless murdering of Black boys and men in a passionate and accessible story. Another example of an informative young adult fiction is Dear Martin (2017) by Nic Stone. Justyce McAllister, a Black teenage boy, writes letters to Dr. Martin Luther King Jr. Readers receive a glimpse into the unfiltered mind of a boy who attempts to mimic Dr King Jr. by taking the moral high ground after being racially profiled, in an important commentary on hatred, racism, and 
prejudice. This novel specifically focuses on society's current view of Black teenagers that are forced to endure harmful profiling, toxic masculinity, and microaggressions. As explained above, young adult books help "navigate and grapple with the political and social issues" of the age in which they are written, and these novels are written in a tone that has been heavily impacted by these themes of disillusionment and displacement (Falconer 6). Millennials often read for nostalgic reasons but for a reader to choose a novel like I Am Alfonso Jones or Dear Martin, goes beyond a simple desire to connect with a childhood naïveté. These novels are a way for millennials to better understand the injustice and prejudice that people of colour face because they are reading an easily understandable narrative that depicts the realities and the inner thought process of what it is like to go through these specific hardships. The irony in this reading is revealed with the fact that millennials are attempting to find agency and safety from these problematic situations that have occurred since well before the twenty-first century. Meanwhile, millennials are striving to escape mentally by reading literature that may not always provide a solution, but that captivates readers with the desire to fight for change.

Since the 1900s, women have marched and created movements to gain agency for their generation and those that follow, so much so that feminism and equality often become part of the generational identity for the youth growing up within the thick of mass demonstrations. The Women's Suffrage movement focused on fighting for women's right to vote and in 1920, the Constitution enfranchised American women so that they could have the agency as American citizens with all of the same rights and responsibilities as men. While women had the right to vote, they did not have true equality which resulted in many more marches for equality occurring, including 1970's Women's Strike for Equality, 1995's Rally for Women's Lives (looking to stop violence against women), and 1997's Million Woman March (in which African- 
American women demanded justice and equality). The most recent Women's Marches (and many other protests and movements, including the \#MeToo Movement), from 2017 to 2020, have focused on President Donald Trump's rise to power, as a direct result of his racism, misogyny, white supremacy, and abuse of power. These protests are ingrained in the generational identity of those who protest and, due to the socio-economic impact on millennials, the generations that come thereafter - Generation Z and Generation Alpha (from 2010 to present)— each have a shared experience. These three generations have focused heavily on speaking out against injustice and have developed with this ideology that the current socio-economic, cultural, and ecological climate has been damaged so thoroughly by the older generations, and that it is the young generations' job to fix it. As millennials, Generation Z, and Generation Alpha take over power from the previous generations, they also take on the plight of each movement and life-changing event. They are necessitated as the ones that must have a much more positive impact so that the next generation can live with less of a burden created by their forefathers. This makes developing one's agency and the meaning of their life difficult, as the focus is on collective protests rather than personal and professional growth. Instead of all millennials taking time to travel, many are donating to worthy causes and marching in protest instead. This constant need to fight for even the most basic human right—like access to abortions and equal payinfluences crossover readers, because when one has no guarantees in life that things will improve, how do they survive that harrowing reality? Many turn to escapist literature to decompress and recharge from their everchanging powerless reality. An example of this escapist tendency is found within Naomi Alderman's The Power (2017), that follows a phenomenon that causes teenage girls to develop a physical power of causing painful sensations and death with the touch of a hand. The patriarchal world that The Power depicts is very similar to the current 
landscape, with misogynistic men holding powerful positions and women fearing for their physical safety. In this alternate world Alderman creates, women are more powerful and twist the patriarchy to a similar ideologized matriarchy. In essence, males are afraid to walk alone at night; a female God is worshipped; women are elected as political leaders; women are the majority in the army; and sex-trafficked women are freed. This is not a depiction of what gender equality would look like in a utopian society but rather focusses on the reality of the horrors of any one gender lording over another in a very realistic portrayal of how the patriarchy functions in twenty-first century America. Similar to classics like Margret Atwood's The Handmaid's Tale (1985) and Aldous Huxley's Brave New World (1932), The Power focuses on a dystopian world where power is being used for evil; interestingly, these three novels all have a misguided idea that those in power have created a utopian society when in reality, the situation is only beneficial to those in power.

Alongside the desire to fight for cultural change cultural disparities and the leadership presented in America that mimics a dystopian landscape, the World Wildlife Foundation explains that the globe's average temperature has increased because of emissions of carbon dioxide and greenhouse gases directly affected by human activity. Global warming emissions are destroying the earth with a rising sea level, coral bleaching, melted ice, heat waves, flooding, and loss of wildlife habitat. Climate protests and marches have occurred worldwide as all generations are attempting to stop governmental inaction to this crisis. This struggle is depicted in Jim Lynch's award-winning young adult novel, The Highest Tide (2005) that follows thirteen-yearold Miles who has a distinct fascination with the ocean and oceanic wildlife. After finding a few animals, a giant squid and a ragfish, washed up on the beach, Miles becomes a local celebrity "prophet." By making his community aware that the bay waters continue to rise an inch every 
year, Miles — and The Highest Tide, in general—brings to the forefront problems surrounding global warming and its direct impact on the oceans. All the while, the novel blends bildungsroman themes of sexuality and puberty with a humbling narrative full of respect and awe imparted on the ocean and its wildlife. Lynch's approachability to the themes included in The Highest Tide truly enhances the relationship between literature and society with a realistic depiction of the effect of a natural disaster that is still very relevant in 2020. Lynch's novel has a very diverse audience because The Highest Tide was published in ten languages. It won the Pacific Northwest Booksellers Association Award without the novel being mentioned as a part of children's literature. Lynch's novel was added as a book club pick by British television show, Richard \& Judy; again, with no mention of the intended target audience. It was also adapted into a play, meant for audiences eleven-years and older, at Harlequin Theatre in Olympia in early 2020 that was quite popular until COVID-19 caused the production to be suspended. The Highest Tide has been popular with many different readers since its release because of its intriguing subject matter and categorization as a crossover novel on book-lover websites like Goodreads.com. The Highest Tide allows readers to engage with a social justice issue within an escapist text.

Similar to twenty-first century young adult literary tropes that instigate change for social justice issues, classic tropes like drug use and relationship angst, similar to those found in The Baby-Sitters Club, are complemented by other tropes such as the protagonist feeling like an 'outsider'; 'The Chosen One' protagonist; love triangles; fake relationships until one protagonist falls in love with another; soul mates; and forbidden love. These tropes can be comforting in their formulaic simplicity and do not include assumed experiences on behalf of the reader. While these young adult texts may be escapist literature, they also confront social realities through the 
tackling of hard-hitting issues. An example of this is Tomi Adeyemi's Children of Blood and Bone (2018); this Nigerian mythology-inspired novel follows Zelie Adebola whose mother is murdered, and her people stripped of their magic (Adeyemi 1). Zelie has to fight the monarchy while struggling to control her powers and her growing feelings for an enemy (Adeyemi 1). This book includes a great representation of a loving and platonic relationship between female characters. Adeyemi also discusses racial and cultural issues of a Nigeria-inspired fantasy country. Not only does this novel explore social power, racial tensions, persecutions, prejudice, and socio-structural inequalities; but, it included tropes like: enemies turn to lovers, princess stuck in a gilded cage, oppressive a 'Big Brother' government, and abusive parents. These basic plot points were reinvented in a diversified way that is reminiscent of twenty-first century issues. Some other titles that have similar plots to Adeyemi's are: Nnedi Okorafor's Akata Witch (2011), and The Cruel Prince (2018) by Holly Black. Young adult literature, told from the perspective of a teenager, empowers readers to realize the agency they have in the world in a way that includes didactic and moralistic content. As many young adult texts and series are transformed into profitable Hollywood franchises including The Hunger Games, Harry Potter, P.S. I Still Love You, The Sun is Also a Star - the potential audience that young adult literature could reach is clear, as it becomes a "guide [as the] hegemonic understanding of society increases exponentially" for viewers and readers (Garcia 3). These writers have written these novels as a response to the cultural and social landscape of the world. This includes themes like displacement and discrimination that are written in an easily understandable way by including common — and often formulaic — themes, clichés, plots and subplots, and tropes woven into a narrative that is intended to be understood by those under eighteen years of age. This is done with the knowledge that these works will invoke a nostalgic refuge for crossover readers. 
Nostalgia can be a very reliable force for readers, especially for those that reread the same texts from their childhood.

But nostalgia is not the only reason adults are reading young adult literature; it is also the "transnational nature of the prose and content" in specific young adult literature like J.K. Rowling's books that "helped turn young adult literature into something that even adults openly embrace" (Garcia 16). The success of Rowling's works has caused a transnationalism as the Harry Potter franchise has had steady success as the highest grossing franchise of all time (Garcia 13). For many, Harry Potter is a "vibrant symbol of the power of young adult literature" in its continuance and steady following (Garcia 13). Harry Potter and the Philosopher's Stone was first released in 1997 with the last in the series, Harry Potter and the Deathly Hallows debuting in 2007. In that ten-year gap, the franchise has had a steady following that aged with the series, especially as the franchise was supposed to culminate with the last film's release in 2011. The consistent spinoffs like Fantastic Beasts and Where to Find Them (2016), video games, mobile games, and plays has continued to keep J. K. Rowling's works in the limelight. People of all ages continue to be interested in Rowling's literature and films, and they are marketed as mainstream popular culture. This mainstreaming allows for all audiences to impartially peruse this genre. Since adults are the primary buyers of this genre, it is likely "publishers are going to focus on the needs and interests of this demographic" over that of the previously intended audience (Garcia 17). This opened up doors for films and books to be accepted and enjoyed by more age-diverse people. This franchise can be considered a millennial concoction, as it developed at the cusp of Generation $\mathrm{Z}$ but expanded worldwide by millennial children reading the series' first. This, I believe, is one of the reasons why millennials continue to pick up books similar to Harry Potter and its subsequent franchise. These books are 
comforting and evoke a nostalgia that continues in millennials as they navigate the world around them. It is clear that young adult literature has interested adults for two generations, illustrated with the figures shown in Bowker's 2012 report that indicates that the biggest market for young adult books is those between the ages of thirty and forty-four. That is equivalent to those born in the years 1968 to 1982 which encompasses elder millennials and the majority of Generation X (1965-1979). Looking at this study, we are able to glean that this interest in young adult literature is not purely a millennial fascination, but the extent of interest outside of young adult literature's targeted age group remains unknown due to the lack of research done in this specific area.

In the limited scope afforded me here, I have argued that many social and cultural movements, protests, and adapting genres_-millennials' crossover literature, Black Lives Matter, The Women's March, and COVID-19 — have all had an impact on both society and young adult literature. Millennials make up around seventy-five million people in America and are forty-four percent minority which makes it one of the "most diverse adult generation, in American history" (Frey). Young adult literature was (and still is) impacted by the generational identity of its intended audience, recently those that have been defined by displacement, loss of identity, racism, and assimilation are the focus of the genre, but it is consumers between the ages of eighteen to forty-four who commonly purchase young adult literature (Pattee 223). Young adult works have been increasingly "embraced by adult readers, adult movie goers, educators, and literary critics" because of the way these "works speak to the greater human condition, and not just to the specific teen experience" (Garcia xi). New adult literature alters our conceptions regarding adolescence and adulthood as the literary boundaries between the two are precariously construed (Pattee 226). As more realistic themes are included in young adult texts, a wider range of understanding and knowledge about the world is written into the pages of each young adult 
novel. By emphasizing the generational identity of millennials as they regress from the typical ideologies of adulthood, millennials are using young adult literature as a form of escapism. Due to the collapse of the economic and socio-cultural norms in recent decades, both millennials and Generation $\mathrm{Z}$ have had to create an identity within an ever-evolving world that lends itself to the idea that adults are engaging in a prolonged childhood. Young adult literature continues to distort the typical themes they use, because of the reality of today's global economy, a "discussion of what is and is not being represented within these books needs to take place" so that this literature can truly reflect the complexities of everyone's existence instead of focussing on a Eurocentric view as the market dictates (Garcia 2). The adaptability and responsiveness of young adult literature will continue to be relevant to future generations as it is based on society's diversified development, especially as novels will continue to instill a sense of urgency in escapist readers to continue to fight for change. Millennials are attracted to young adult fiction as a form of escapism because there is a nostalgic quality in the formulaic simplicity but also because it allows them to engage with socio-economic and social justice issues in a comprehensive narrative. 


\section{References}

“2012 - Young Adult Books Attract Growing Numbers of Adult Fans.” Bowker, Thorpe-Bowker, 13 Sept. 2012, www.bowker.com/news/2012/Young-Adult-Books-Attract-GrowingNumbers-of-Adult-Fans.html.

Adeyemi, Tomi. Children of Blood and Bone. Macmillan Children’s Books, 2019.

Anggraini, Theresia E. The Characteristics of Child-to-Adult Crossover Literature, The Ohio State University, Ann Arbor, 2015. ProQuest, http://ezproxy.lib.ryerson.ca/login?url=https://search-proquestcom.ezproxy.lib.ryerson.ca/docview/1769007303 ?accountid=13631.

Collins, Sean. "Why the Covid-19 Economy Is Particularly Devastating to Millennials, in 14 Charts.” Vox, Vox, 5 May 2020, www.vox.com/2020/5/5/21222759/covid-19-recessionmillennials-coronavirus-economic-impact-charts.

Falconer, Rachel. The Crossover Novel: Contemporary Children's Fiction and Its Adult Readership, Taylor \& Francis Group, 2008. ProQuest Ebook Central, https://ebookcentral-proquestcom.ezproxy.lib.ryerson.ca/lib/ryerson/detail.action?docID=355891.

Frey, William H. The Millennial Generation: A Demographic Bridge to America's Diverse

Future. 7 May 2018, www.brookings.edu/research/millennials/.

Garcia, Antero. Critical Foundations in Young Adult Literature: Challenging Genres. SensePublishers, 2013. https://doi-org.ezproxy.lib.ryerson.ca/10.1007/978-94-6209-398$\underline{0}$

Greenwell, Amanda M. "“Unsuitable” Books: Young Adult Fiction and Censorship by Caren J. 
Town, and: Literary Conceptualizations of Growth: Metaphors and Cognition in Adolescent Literature by Roberta Seelinger Trites (Review)." Children's Literature (Storrs, Conn.), vol. 43, no. 1, 2015, pp. 317-324.

Hirchberg, Shimona. “The Impact of COVID-19 on Reading.” BookNet Canada, BookNet Canada, 15 Apr. 2020, www.booknetcanada.ca/blog/2020/4/15/the-impact-of-covid-19-onreading.

Hoffower, Hillary. "Meet the Average American Millennial, Who has an \$8,000 Net Worth, is Delaying Life Milestones because of Student-Loan Debt, and Still Relies on Parents for Money." Business Insider, Feb 27, 2020. ProQuest, http://ezproxy.lib.ryerson.ca/login?url=https://search-proquestcom.ezproxy.lib.ryerson.ca/docview/2393611432? accountid=13631.

Johnson, Devon, Patricia Y. Warren, and Amy Farrell. Deadly Injustice: Trayvon Martin, Race, and the Criminal Justice System. New York University, New York, 2015.

Latrobe, Kathy H., and Judy Drury. Critical Approaches to Young Adult Literature. NealSchuman Publishers, 2009.

Mullangi S, Jagsi R. Imposter Syndrome: Treat the Cause, Not the Symptom. JAMA. 2019;322(5):403-404. doi:10.1001/jama.2019.9788

Munley, Patrick H. “Erik Erikson's Theory of Psychosocial Development and Vocational Behavior.” Journal of Counseling Psychology, vol. 22, no. 4, July 1975, pp. 314-319, doi:10.1037/h0076749.

Murray, Joseph L., and Jeffrey Jensen Arnett. Emerging Adulthood and Higher Education : A New Student Development Paradigm. Routledge, 2019. EBSCOhost, search.ebscohost.com/login.aspx ?direct=true \&db=nlebk\&AN=1877777\&site=ehost-live. 
"New Study: 55\% of YA Books Bought by Adults." Publishers Weekly, 13 Sept. 2012, https://www.publishersweekly.com/pw/by-topic/childrens/childrens-industrynews/article/53937-new-study-55-of-ya-books-bought-by-adults.html.

Nova, Annie. "Which Bills to Pay during the Coronavirus Pandemic." CNBC, CNBC, 1 Apr. 2020, www.cnbc.com/2020/03/31/in-the-pandemic-some-of-your-bills-can-wait-and-somecant.html.

“Our Planet Is Warming. Here's What's at Stake If We Don't Act Now.” WWF, World Wildlife Fund, www.worldwildlife.org/stories/our-planet-is-warming-here-s-what-s-at-stake-if-wedon-t-act-now.

Pattee, Amy. "Between Youth and Adulthood: Young Adult and New Adult Literature." Children's Literature Association Quarterly, vol. 42 no. 2, 2017, p. 218-230. Project MUSE, doi:10.1353/chq.2017.0018.

"Publishing Statistics on Children's/YA Books about People of Color and First/Native Nations and by People of Color and First/Native Nations Authors and Illustrators." Children's Books by and About People of Color, Cooperative Children's Book Center School of Education, University of Wisconsin-Madison, 21 Nov. 2019, https://ccbc.education.wisc.edu/books/pcstats.asp

Rosenberg, Alyssa. 'From 'Harry Potter' to 'Twilight,' the Enduring Draw of Young Adult Fiction.” The Atlantic, Atlantic Media Company, 31 May 2011, www.theatlantic.com/entertainment/archive/2011/05/from-harry-potter-to-twilight-theenduring-draw-of-young-adult-fiction/239639/.

Slater, Charles L. "Generativity Versus Stagnation: An Elaboration of Erikson's Adult Stage of Human Development." Journal of Adult Development, vol. 10, no. 1, 2003, pp. 53-65. 
Staff, newsone. “67 Black Men And Boys Killed By Police.” News One, News One, 16 Nov. 2019, https://newsone.com/playlist/black-men-boy-who-were-killed-by-police/item/22.

Webster, N. (1977). The Merriam-Webster dictionary. New York: Pocket Books.

Whitman, Stacy. "A Publisher Reflects on the Blurred Line Between Middle Grade and YA.” Publishers Weekly, PWxyz, LLC., 11 Dec. 2018, www.publishersweekly.com/pw/bytopic/childrens/childrens-industry-news/article/78802-a-publisher-reflects-on-the-blurredline-between-middle-grade-and-ya.html.

Woods, Brianna. "Millenials are Today's Corporate Counterculture." University Wire, 2014. http://ezproxy.lib.ryerson.ca/login?url=https://search-proquestcom.ezproxy.lib.ryerson.ca/docview/1625887032 accountid=13631 